\title{
SECAGEM EM LEITO DE JORRO DA POLPA DE GRAVIOLA COM ADIÇÃO DE LEITE. EFEITO DAS VARIÁVEIS DE OPERAÇÃO SOBRE A TAXA DE PRODUÇÃO E UMIDADE DO PÓ
}

\author{
I. P. MACHADO ${ }^{1}$, A. E. da S. FERREIRA ${ }^{2}$, A. K. T. MACHADO ${ }^{2}$, T. M. DELMIRO ${ }^{2}$ e M. de F. D. \\ de MEDEIROS ${ }^{1}$ \\ ${ }^{1}$ Universidade Federal do Rio Grande do Norte, Programa de Pós-graduação em Engenharia Química \\ ${ }^{2}$ Universidade Federal do Rio Grande do Norte, Departamento de Engenharia Química \\ E-mail para contato: izadora2804@hotmail.com
}

\begin{abstract}
RESUMO - A graviola (A. muricata) vem sendo estudada para avaliar o poder de certos constituintes com ação antitumoral. $\mathrm{O}$ leito de jorro se destaca na secagem de frutas e leite como um método barato e eficaz. A adição do leite a graviola melhora o rendimento do processo sendo desnecessária a utilização de outros aditivos. O secador é formado por uma coluna cônica cilíndrica contendo partículas de polipropileno como inerte. Os ensaios foram baseados num planejamento experimental fracionário $2^{4-1}$, onde se avaliou o efeito das variáveis independentes (temperatura, vazão do ar, tempo de intermitência, e concentração do leite) sobre o rendimento, umidade do pó e taxa de produção. O ensaio com maior concentração de leite e na menor temperatura destacou-se com um rendimento de $42,7 \%$ e taxa de produção de $0,302 \mathrm{~g} / \mathrm{min}$. A concentração, temperatura e vazão do ar mostraram-se significativas para o rendimento e taxa de produção conforme análise estatística realizada com o software Statistica7.0.
\end{abstract}

\section{INTRODUÇÃO}

O Brasil é um grande produtor de frutas, isto se deve a sua extensão territorial, posição geográfica e condição climática. A graviola, da espécie Annona muricata L, apesar de ser pouco explorada economicamente é uma fruta muito apreciada na região Nordeste. Tem uma curta safra e rápida degradação. As áreas produtoras estão instaladas principalmente nas regiões litorâneas e semiáridas do Nordeste (São-José et al., 2000). Geralmente é consumido na forma de suco, doces, geleias, sorvetes, iogurtes entre outros. A fruta possui altos valores de carboidratos e baixos teores de gorduras e valor proteico nas suas sementes. Rios (2013) estudou o potencial antitumoral do extrato acetônico presente nestas.

O leito de jorro tem grande destaque na secagem de polpas de frutas. Sousa (2009) estudou a secagem em leito de jorro de uma mistura de frutas (manga, umbu e siriguela) e conseguiu um rendimento da produção de pó de 59,2\%, valor considerado elevado para a secagem de alimentos de origem vegetais na forma de pastas e suspensões. Para a secagem do leite em leito de jorro os resultados reportados na literatura também são satisfatórios (Urbano et al., 2009). 


\section{9 a 22 de outubro de 2014 \\ Florianópolis/SC}

Em testes preliminares de secagem da polpa de graviola pura, ocorreram problemas de instabilidade e baixos rendimentos, inviabilizando a secagem no leito de jorro. Braga e Rocha (2013) utilizaram o leite como aditivo na secagem de amora, resultando no aumento do rendimento e da qualidade do produto em pó. Considerando-se os resultados dos testes preliminares e os reportados na literatura optou-se por adicionar o leite à polpa de graviola, realizando-se o estudo da secagem desta mistura.

O presente trabalho tem como objetivo avaliar o processo de secagem da polpa de graviola com adição de leite integral, analisando o rendimento do processo, taxa de produção e umidade do pó em função da concentração do leite, temperatura, vazão do ar e tempo de intermitência na alimentação da mistura.

\section{REVISÃO BIBLIOGRÁFICA}

\subsection{Leito de Jorro}

O leito de jorro é uma técnica de secagem que foi criada para desidratação de grãos. Hoje em dia ganha destaque na produção de frutas em pó. A vantagem do método consiste no baixo custo operacional do equipamento produzindo em pequena escala um pó com características compatíveis com os de secadores tipo spray (Rosa et al., 2010).

Segundo Grbavcic et al. (2000), para um sistema de secagem ser considerado eficiente, algumas condições devem ser atendidas: valores elevados de coeficientes de transferência de calor e massa, grande área de contato, fornecimento elevado de calor pelo gás de secagem, temperatura uniforme ao longo da câmara de secagem, injeção de suspensões concentradas para reduzir a quantidade de água a ser evaporada e emprego de ar com temperaturas elevadas na entrada.

Freire e Ferreira (2012) determinou que a estabilidade do processo está relacionada a variáveis como a taxa de alimentação, da composição e do grau de saturação da pasta. Nascimento (2013) estudou a influência de teores de açúcar e gordura da pasta em relação a vazão de alimentação. Constatou que maiores valores de gordura proporcionaram maiores vazões de alimentação, em relação aos teores de açúcar não houve alteração nas vazões.

\section{MATERIAIS E MÉTODOS}

\subsection{Preparo das Misturas}

As frutas foram compradas em mercado local e despolpadas manualmente. A polpa foi homogeneizada em liquidificador e peneirada para eliminação de alguns resquícios de casca e caroço que posteriormente causariam danos na alimentação do processo. Foi separada em pequenas porções e armazenada em freezer. O leite utilizado foi o integral de caixa, adquirido em mercado local.

Determinou-se a umidade e teor de sólidos solúveis $\left({ }^{\circ}\right.$ Brix $)$ da polpa, leite e mistura. A análise de umidade foi realizada em estufa até peso constante e as de sólidos solúveis em refratômetro digital. 


\subsection{Secagem}

O diagrama esquemático da unidade de secagem encontra-se na Figura 1. A alimentação do ar é feita pela parte inferior da coluna a uma velocidade que venha a provocar o movimento ascendente das partículas contidas no interior do leito. A mistura é alimentada de forma atomizada dentro da coluna, formando uma fina camada envolvendo as partículas, que é secada pela passagem do ar quente. $\mathrm{O}$ atrito entre os inertes durante o movimento do jorro rompe essas películas formando o pó que é arrastado pelo ar. O pó é coletado por um ciclone acoplado na saída da coluna.

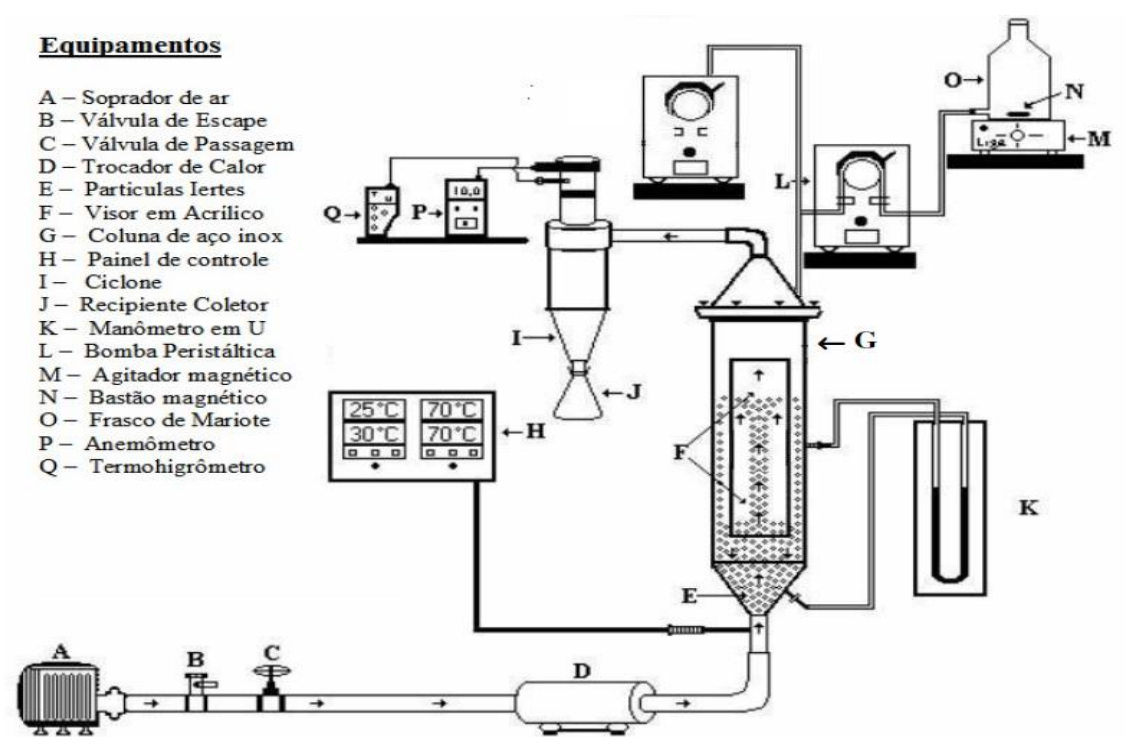

Figura 1 - Diagrama esquemático do secador. (Sousa, 2009)

O secador utilizado consta de uma coluna cilíndrica $(18 \mathrm{~cm}$ de diâmetro e $72 \mathrm{~cm}$ de altura), base cônica (ângulo incluso de $60^{\circ}$, altura de $13 \mathrm{~cm}$ e diâmetro de entrada de $3 \mathrm{~cm}$ ), acoplado a um ciclone do tipo Lapple para separação e coleta do pó. O ar é fornecido através de um soprador centrífugo de $7 \mathrm{cv}$, sendo aquecido por um trocador de calor (resistência elétrica de $2000 \mathrm{~W}$ de potência) em conjunto com um sistema de controle de temperatura. Na saída do ar do ciclone são realizadas as medidas de vazão, temperatura e umidade do ar utilizando-se termopar, anemômetro e termo higrômetro digitais, respectivamente. Para alimentação da polpa utiliza-se um sistema composto por uma bomba peristáltica e um bico atomizador.

Utilizou-se como material inerte uma carga de $2500 \mathrm{~g}$ de partículas de polietileno de alta densidade com diâmetro de $0,3184 \mathrm{~cm}$ e densidade $1,087 \pm 0,436 \mathrm{~g} / \mathrm{mL}$. A densidade das partículas foi determinada por picnometria líquida, utilizando-se picnômetros previamente calibrados e álcool etílico. O diâmetro das partículas corresponde ao diâmetro da esfera de igual volume deslocado. As medidas foram realizadas em quadruplicada. Foi obtida a curva característica do leito, com determinação da velocidade de jorro mínimo, conforme a metodologia usualmente empregada e relatada na literatura (Sousa, 2009). A velocidade de jorro mínimo (Uj) obtida foi de $10 \mathrm{~m} / \mathrm{s}$. 
Os experimentos foram realizados com alimentação intermitente das misturas. O tempo de intermitência corresponde à soma dos tempos de alimentação e parada. A vazão de alimentação permaneceu em $8 \mathrm{~mL} / \mathrm{min}$, sendo realizadas 6 alimentações por ensaio. Para padronizar a massa total alimentada no processo com o tempo de intermitência, fixou-se o tempo de alimentação em 6 min e variou-se o tempo de parada nos ensaios em 4, 6 e 8 min.

Os ensaios foram realizados para diferentes condições de concentração de leite na mistura, temperatura, tempo de intermitência e de velocidade do ar normalizada em relação a velocidade de jorro mínimo (U/Uj), de acordo com um planejamento experimental fracionário do tipo $2^{4-1}$. As condições experimentais arranjadas conforme as diferentes combinações previstas pelo planejamento são apresentadas na Tabela 1.

Tabela 1 - Condições operacionais dos ensaios de secagem conforme o planejamento experimental fracionário $2^{4-1}$

\begin{tabular}{lllll}
\hline ENSAIO & $\begin{array}{l}\text { Conc. Leite } \\
(\%)\end{array}$ & $\begin{array}{l}\text { Temperatura } \\
\left({ }^{\circ} \mathrm{C}\right)\end{array}$ & $\begin{array}{l}\text { Tempo Inter. } \\
(\mathrm{min})\end{array}$ & $\begin{array}{l}\text { Vazão Ar } \\
(\mathrm{U} / \mathrm{Uj})\end{array}$ \\
\hline 1 & $30(-1)$ & $70(-1)$ & $10(-1)$ & $1,2(-1)$ \\
2 & $50(1)$ & $90(1)$ & $10(-1)$ & $1,2(-1)$ \\
3 & $50(1)$ & $70(-1)$ & $14(1)$ & $1,2(-1)$ \\
4 & $30(-1)$ & $90(1)$ & $14(1)$ & $1,2(-1)$ \\
5 & $50(1)$ & $70(-1)$ & $10(-1)$ & $1,5(1)$ \\
6 & $30(-1)$ & $90(1)$ & $10(-1)$ & $1,5(1)$ \\
7 & $30(-1)$ & $70(-1)$ & $14(1)$ & $1,5(1)$ \\
8 & $50(1)$ & $90(1)$ & $14(1)$ & $1,5(1)$ \\
\hline
\end{tabular}

As amostras de pó foram coletadas tanto durante o tempo de alimentação como no período em que a alimentação foi suspensa. Esses dados foram utilizados para determinar a taxa de produção do pó. As amostras eram pesadas e depois misturadas para determinação da umidade média do pó. As medidas foram realizadas em balança com infravermelho a temperatura de $70^{\circ} \mathrm{C}$ por 90 minutos.

O rendimento da secagem foi obtido pela Equação 1, e é dado pela razão entre a massa de pó produzido e a massa alimentada, ambas expressas em base seca.

$$
\text { Rend }=\frac{m_{p o}\left(1-x_{p o}\right)}{m_{\text {alim }}\left(1-x_{\text {mist }}\right)}
$$

Onde: $m_{\text {pó }}$ é a massa de pó produzido, $m_{\text {alim }}$ é a massa alimentada da mistura, $x_{\text {pó }}$ a umidade do pó obtido e $x_{\text {mist }}$ a umidade da mistura alimentada.

\section{RESULTADOS E DISCUSSÕES}

Determinaram-se valores médios de umidade e sólidos solúveis da polpa homogeneizada, leite e 
das misturas com 30 e $50 \%$ de leite. Os resultados apresentados na Tabela 2 condizem com o esperado. A adição do leite com menor concentração de sólidos solúveis e maior teor de umidade resulta em misturas mais úmidas e com menor teor de sólidos solúveis do que a polpa original. Importante se faz citar que as polpas in naturas apresentaram variações no teor de umidade devido às variações nas condições fisiológicas da fruta.

Tabela 2 - Caracterização de fruta, leite e misturas

\begin{tabular}{lcc}
\hline & Umidade $(\%)$ & Sólidos solúveis $\left({ }^{\circ}\right.$ Brix \\
\hline Fruta & 84,81 & 15,94 \\
Leite & 87,60 & 12,65 \\
Mistura (30\% L) & 85,33 & 13,64 \\
Mistura (50\% L) & 85,73 & 12,35 \\
\hline
\end{tabular}

Nas Figuras 2, 3, 4 e 5 estão ilustrados os dados de massa de pó produzida em função do tempo. O comportamento linear das curvas observadas sugere produção à taxa constante. Nas Figuras 2 e 3 são representados os dados da produção de pó para os experimentos realizados na temperatura de 70 e $90^{\circ} \mathrm{C}$ respectivamente. Na Figura 2 verifica-se o importante efeito da concentração de leite combinada com o maior nível de vazão do ar no sentido de aumentar a produção. Nas condições opostas de vazão e concentração de leite, os efeitos se anulam, as retas são coincidentes, o que implica em produções iguais. Na condição de menor vazão e concentração de leite a produção de pó diminui. Na Figura 3 o comportamento se repete, todavia a produção de pó é mais baixa, indicando o efeito negativo da temperatura sobre esta variável. Observa-se ainda que o tempo de intermitência não apresenta influência sobre a produção de pó. Para a mesma temperatura as menores e maiores produções foram verificadas nos mesmos tempos de intermitência.

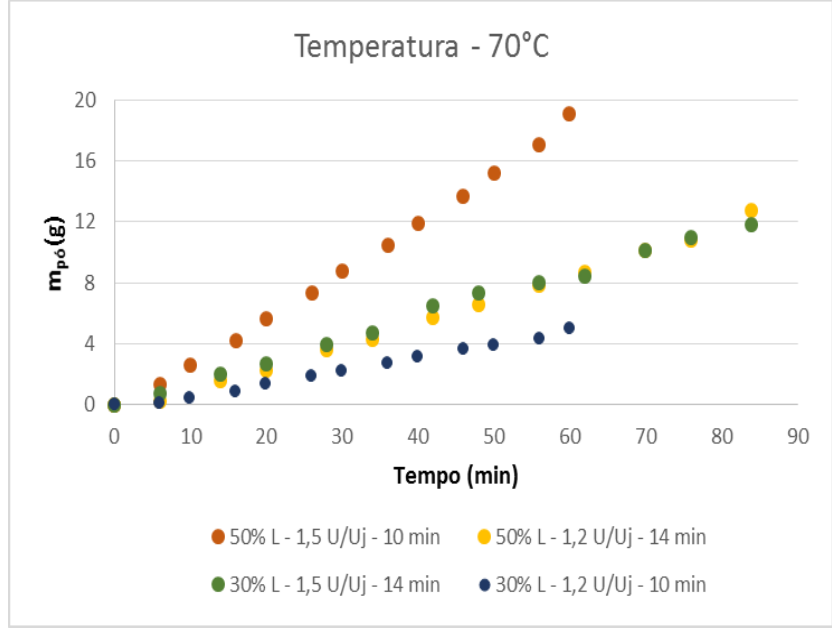

Figura 2 - Gráficos de massa produzida em função do tempo a temperatura de $70^{\circ} \mathrm{C}$

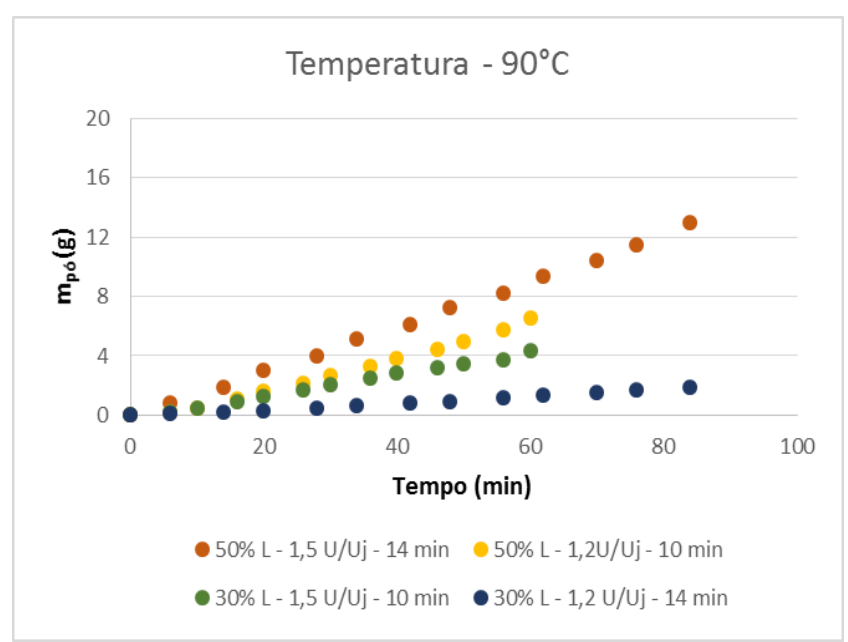

Figura 3 - Gráficos de massa produzida em função do tempo a temperatura de $90^{\circ} \mathrm{C}$ 


\section{9 a 22 de outubro de 2014 \\ Florianópolis/SC}

Nas Figuras 3 e 4 avaliam-se os efeitos da temperatura e concentração para vazões de ar fixas. Em consonância com a discussão anterior as maiores produções de pó são observadas nos experimentos realizados na temperatura mais baixa e com maior adição de leite. Destaca-se a coincidência das curvas quando a mistura foi processada em condições opostas de temperatura e concentração. A influência negativa da temperatura sobre a produção de pó na faixa de condições de operação em que foram realizados os experimentos pode ser explicada com base na teoria da transição vítrea. Frutas com elevada concentração de açúcares geralmente apresentam temperatura de transição vítrea baixa, comprometendo o processo de secagem no leito de jorro (Bhandari \& Adhikari, 2009). A temperatura de $90^{\circ} \mathrm{C}$ pode está próxima da temperatura de transição da graviola. Ressalta-se que a influência positiva da adição do leite pode ser explicada tanto pelo aumento na temperatura de transição vítrea da mistura como pela influência da elevada concentração de gordura presente no leite integral. (Nascimento, 2013).

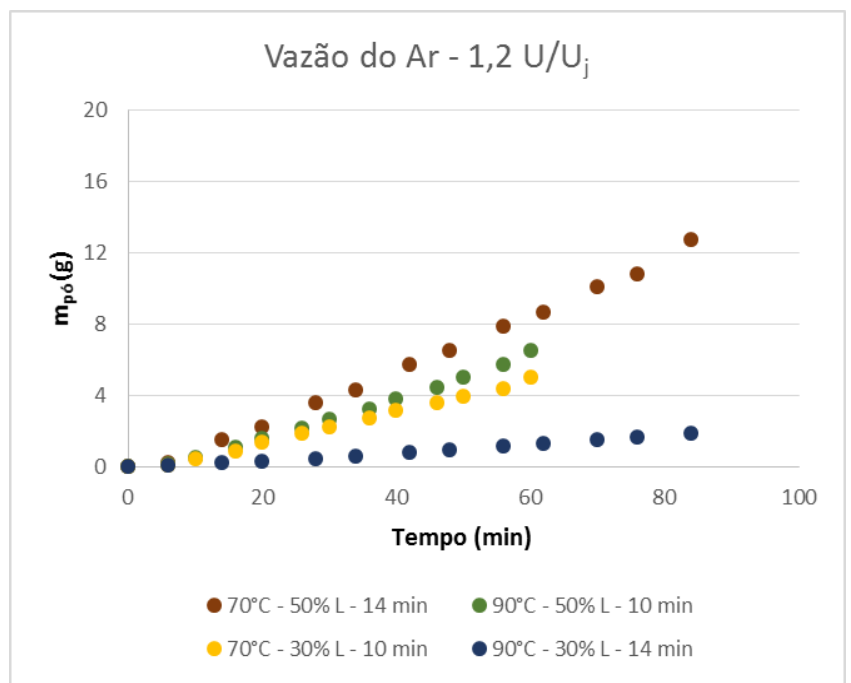

Figura 4 - Gráficos de massa produzida em função do tempo a vazão de ar de $1,2 \mathrm{U} / \mathrm{Uj}$

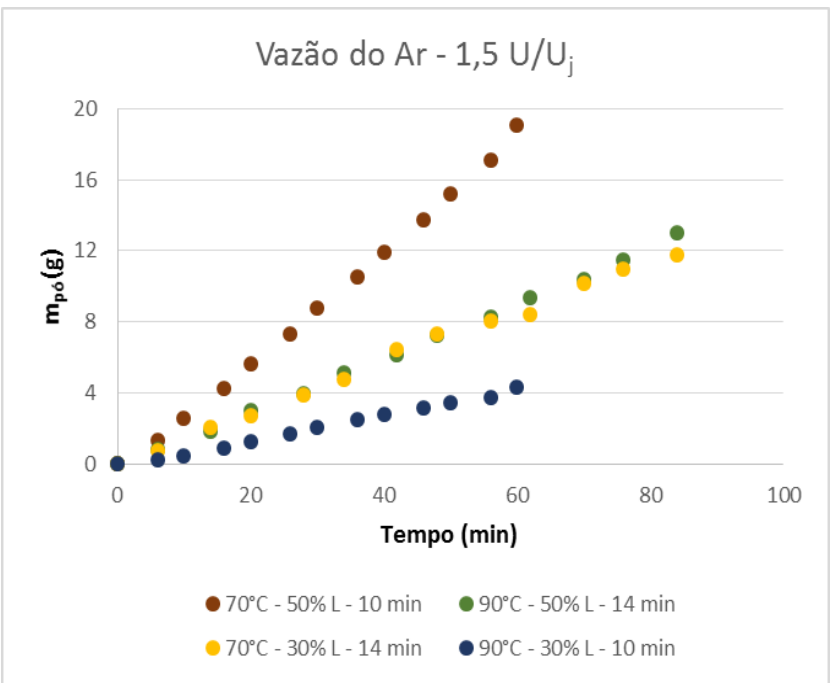

Figura 5 - Gráficos de massa produzida em função do tempo a vazão de ar de 1,5U/Uj

Determinou-se a taxa de produção em cada experimento a partir da linearização da curva massa produzida em função do tempo, utilizando planilhas eletrônicas. O modelo linear se ajustou muito bem aos dados experimentais, o $\mathrm{R}^{2}$ médio foi de $0,9893 \pm 0,0086$, confirmando a taxa de produção do pó constante.

Na Tabela 3 apresentam-se os resultados da umidade do pó, rendimento e taxa de produção. O ensaio 5 se destaca com rendimento de $42,7 \%$ e taxa de produção de $0,302 \mathrm{~g} / \mathrm{min}$. Os valores da umidade não apresentam grandes variações, apenas os ensaios 6, 7 e 8 não se encontram na faixa dos demais, entre 6,00 e 6,72 \% em base úmida. O rendimento mínimo de 4,75\% foi obtido no experimento 4 quando as condições de operação se combinaram nos níveis mais desfavoráveis ao processo: maior temperatura, menor concentração de leite e vazão do ar. Inversamente no experimento 5 a combinação das condições mais favoráveis levou a um rendimento de 42,7 \%, considerado elevado para a secagem de polpas de frutas em leito de jorro. 
Tabela 3 - Resultado das variáveis respostas.

\begin{tabular}{llllllll}
\hline ENSAIO & $\begin{array}{l}\text { Conc. L } \\
(\%)\end{array}$ & $\begin{array}{l}\mathrm{T} \\
\left({ }^{\circ} \mathrm{C}\right)\end{array}$ & $\begin{array}{l}\text { T.I. } \\
(\mathrm{min})\end{array}$ & $\begin{array}{l}\text { Vaz. Ar } \\
(\mathrm{U} / \mathrm{Uj})\end{array}$ & $\begin{array}{l}\text { Umid } \\
(\%)\end{array}$ & $\begin{array}{l}\text { Rend } \\
(\%)\end{array}$ & $\begin{array}{l}\text { T. de Prod } \\
(\mathrm{g} / \mathrm{min})\end{array}$ \\
\hline 1 & $30(-1)$ & $70(-1)$ & $10(-1)$ & $1,2(-1)$ & 6,39 & 16,52 & 0,077 \\
2 & $50(1)$ & $90(1)$ & $10(-1)$ & $1,2(-1)$ & 6,17 & 16,02 & 0,098 \\
3 & $50(1)$ & $70(-1)$ & $14(1)$ & $1,2(-1)$ & 6,72 & 31,76 & 0,142 \\
4 & $30(-1)$ & $90(1)$ & $14(1)$ & $1,2(-1)$ & 6,00 & 4,75 & 0,021 \\
5 & $50(1)$ & $70(-1)$ & $10(-1)$ & $1,5(1)$ & 6,24 & 42,65 & 0,302 \\
6 & $30(-1)$ & $90(1)$ & $10(-1)$ & $1,5(1)$ & 5,43 & 10,95 & 0,069 \\
7 & $30(-1)$ & $70(-1)$ & $14(1)$ & $1,5(1)$ & 7,11 & 29,88 & 0,143 \\
8 & $50(1)$ & $90(1)$ & $14(1)$ & $1,5(1)$ & 4,18 & 36,28 & 0,150 \\
\hline
\end{tabular}

A análise dos resultados foi realizada através de métodos estatísticos utilizando-se o software Statistica 7.0. Na Tabela 4 são apresentados os efeitos principais das variáveis independentes tendo como respostas o rendimento, umidade e taxa de produção de pó, para um modelo de $1^{\circ}$ ordem sem considerar as interações entre as variáveis, com um limite de confiança de $95 \%$. As interações entre as variáveis independentes não foram consideradas em virtude de se tratar de um planejamento fatorial fracionário, cujos efeitos das interações se confundem com os efeitos principais.

Tabela 4 - Equações das taxas de produção e respectivos ajustes

\begin{tabular}{llcc}
\hline \multirow{2}{*}{ Variáveis independents } & \multicolumn{3}{c}{ Respostas } \\
\cline { 2 - 4 } & Rend (\%) & Umidade $(\%)$ & T. de Prod (g/min) \\
\hline Conc. de leite & $16,1497^{*}$ & $-0,405$ & $0,09575^{*}$ \\
Temperatura & $-13,2032^{*}$ & $-1,170$ & $-0,08120^{*}$ \\
Tempo de intermitência & 4,1379 & $-0,055$ & $-0,02215$ \\
Vazão do ar & $12,6813^{*}$ & $-0,580$ & $0,08160^{*}$ \\
$\mathrm{R}^{2}$ & 0,9788 & 0,6664 & 0,9244 \\
\hline
\end{tabular}

* Efeitos com significância estatística

Conforme se observa na Tabela 4, a variável tempo de intermitência não apresenta efeito significativo sobre qualquer uma das variáveis resposta. Os efeitos da adição de leite e vazão do ar sobre o rendimento e taxa de produção de pó são significativos e positivos, já o efeito da temperatura é negativo. Em valores absolutos o efeito da concentração de leite é o mais importante, enquanto os efeitos da temperatura e da vazão apresentam intensidades semelhantes. A umidade do pó não sofreu influência significativa das variáveis independentes na faixa de condições experimentais empregada. Os resultados da análise estatística condizem com toda a discussão apresentada anteriormente.

\section{CONCLUSÃO}

A adição do leite e maior vazão do ar favoreceram o rendimento e taxa de produção de pó enquanto a elevação da temperatura prejudicou o desempenho do processo. A análise estatística confirmou a significância dos efeitos da temperatura, vazão do ar e concentração de leite sobre as 


\section{9 a 22 de outubro de 2014 \\ Florianópolis/SC}

variáveis rendimento e taxa de produção, comprovando também que para o intervalo operativo dos experimentos o tempo de intermitência não influenciou significativamente qualquer uma das variáveis analisadas. A umidade do pó não sofreu influência significativa das variáveis de operação, obtendo-se valor médio de $6,030 \pm 0,896 \%$. Os resultados do presente trabalho indicam a viabilidade do processo de secagem (polpa+leite) no leito de jorro. Necessário se faz ampliar o delineamento experimental para um fatorial completo com réplicas no ponto central, para que seja possível uma análise mais precisa dos efeitos das variáveis principais e de suas interações sobre o desempenho do processo.

\section{REFERÊNCIAS}

BHANDARI, B.; ADHIKARI, B. Glass-Transition Based Approach. In: RATTI, C. Drying of Foods: Advances in Food Dehydration. Nova Iorque: Taylor \& Francis Group, 2009. P.123-156.

BRAGA, M. B.; ROCHA, S. C. S.; Drying of milk-blackberry pulp mixture in spouted bed; The Canadian Journal of Chemical Engineering, v.91, p.1786-1792, 2013

FREIRE, J. T; FREIRE, F. B.; FERREIRA, M. C.; NASCIMENTO, B. S. A hybrid lumped parameter/neural network model for spouted bed drying of pastes with inert particles. Drying Technology, v.30, n. 6, p.1342-1353, 2012.

GRBAVCIC, Z. B.; ARSENIJEVIC, Z. L. J.; GARIC-GRULOVIC, R. V. Drying of suspension and pastes in fluidized bed of inert particles. Journal of the Serbian Chemical Society, v.65, n.12, p.963974, 2000.

NASCIMENTO, B. S. Análise do efeito da composição química na secagem de pasta em leito de jorro. 2013. Doutorado em Engenharia Química - Universidade Federal de São Carlos, SP.

RIOS, M. E. F.; Estudo da atividade citotóxica e do potencial anti-tumoral do extrato acetônico das sementes de Annona muricata L.(AMSA), em modelos experimentais in vitro e in vivo. Mestrado em Farmacologia - Universidade Federal do Ceará, Fortaleza, 2013.

ROSA, C. A. Estudo experimental e numérico da fluidodinâmica e das transferências de calor e massa em um leito de jorro contínuo: uso da técnica CFD. 2010. 97f. Doutorado em Engenharia Química Universidade Federal de São Carlos, São Carlos.

SÃO-JOSÉ, A.R.; ANGEL, D.N.; BONFIM, M.P.; REBOUÇAS, T.N.H. Cultivo da graviola. In: Semana Internacional de Fruticultura e Agroindústria, 2000, Fortaleza.

SOUZA, J. S. Secagem de misturas de polpas de frutas tropicais em leito de jorro. 2009b, 156f. Doutorado em Engenharia Química - Universidade Federal do Rio Grande do Norte, Natal.

URBANO, E. A., SOUZA JR., F. E., MEDEIROS, U. K. L., MEDEIROS, M. F. D., "Leite de cabra em pó produzido em leito de jorro: propriedade do pó". VIII Congresso Brasileiro de Engenharia Química em Iniciação Científica - COBEQ IC, 2009, Uberlândia - Minas Gerais. 